\title{
Specific Mathematics Learning Objectives Expressed by Teachers in Training
}

\author{
Elena Castro-Rodríguez ${ }^{1 *} \mathbb{E}$, Juan F. Ruiz-Hidalgo ${ }^{1} \mathbb{D}$, Jose L. Lupiáñez ${ }^{1} \mathbb{( D}$, Jose A. Fernández-Plaza ${ }^{1}(\mathbb{D}$, \\ Luis Rico $^{1}$ (D) Isidoro Segovia ${ }^{1} \mathbb{D}$, Pablo Flores $^{1}$ (D)
}

${ }^{1}$ Universidad de Granada, SPAIN

*Corresponding Author: elenacastro@ugr.es

Citation: Castro-Rodríguez, E., Ruiz-Hidalgo, J. F., Lupiáñez, J. L., Fernández-Plaza, J. A., Rico, L., Segovia, I., \& Flores, P. (2022). Specific Mathematics Learning Objectives Expressed by Teachers in Training. International Electronic Journal of Mathematics Education, $17(2)$, em0675. https://doi.org/10.29333/iejme/11670

\section{ARTICLE INFO}

Received: 1 Mar. 2021

Accepted: 9 Jun. 2021

\begin{abstract}
The formulation of learning objectives is considered an important task for teaching at all educational levels. However, teachers tend to trivialize learning objectives and consider them as part of an administrative requirement. This study sought to characterize the specific learning objectives for two school mathematics tasks posed by primary teachers in training, and to study the differences in the objectives proposed for each task. By means of a semantic questionnaire, the proposals were collected, classified and analysed using categories based on a triad of components for a specific objective: capability, content, and context. The responses show both an instrumental approach-where knowledge consists in mastering techniques and algorithms useful to furthering certain behaviours and attaining specific objectives-and a structural approach-where knowledge consists in a structured system of formalized rules and concepts based on the deduction. Moreover, this expectation depends on the kind of school task.
\end{abstract}

Keywords: learning expectations, mathematics tasks, prospective primary teachers, teacher education

\section{INTRODUCTION}

Mathematics teaching is acknowledged to be a demanding and difficult profession, requiring knowledge and understanding drawing from several disciplines (Putra, 2019). Only in the last few decades, precise descriptions of the specific contents and competences that should be addressed in pre-service mathematics teacher training and its present shortcomings have been amply studied (Carrillo, Climent, \& Contreras, 2013; Petrou \& Goulding, 2011).

Among the competencies of teachers, one of the most remarkable is classroom planning, a rational process focused on anticipating the students' learning process by designing teaching sequences and providing articulated resources and reasoned responses to achieve the purposes of education by means of mathematics content (Landmann, 2013; Rico \& Ruiz-Hidalgo, 2018). When planning school mathematics, teachers select and declare their learning expectations involved in the acquisition and development of knowledge, capabilities and attitudes of students.

The formulation of learning expectations, the basis for planning in compulsory education, is the outcome of many decades of effort. Though managing learning expectations is currently considered an important task for teaching at all educational levels (Hiebert, Morris, \& Spitzer, 2018), teachers tend to consider the objectives as part of an administrative requirement, usually avoiding them or appropriating objectives already proposed (DeLong, Winter, \& Yackel, 2005b). Even today "learning objectives have tended to become so trivialized and generalized that they communicate little more than the topic to be covered" (Gander, 2006, p. 9).

Research on the topic has focused on provided firm empirical support for the relationship between the approach adopted in learning expectations and students' performance in mathematics (e.g., Chen, Reys, \& Reys, 2009; Lin et al., 2009). Findings highlight that learning goals orientation was much more significant than socioeconomic status in predicting student performance in mathematics (Lin et al., 2009), and condition the tasks assigned to students (Chen et al., 2009). In addition, the classroom implementation of a mathematical task is influenced by the teachers' objectives, and when they are clear about the expectations of the task, the learning of the students can increase (Aguayo-Arriagada, Flores, \& Moreno, 2018; Sullivan et al., 2010).

Other investigations have focused on expectations in relation to teacher planning (e.g., DeLong, Winter, \& Yackel, 2005a; Delong et al., 2005b; Lupiáñez \& Rico, 2011). De Long, Winter, and Yackel (2005a, 2005b) analysed which aspects of two methods of systematic goal generation are well suited to planning for university-level mathematics courses. In relation to pre-service 
teachers, Lupiáñez and Rico (2011) implement and analyse a training program for secondary pre-teachers based on the planning of teaching. Their results reveal that after the training received, the participants are able to enunciate specific objectives, interpret the objectives of other participants, and enunciate tasks linked to objectives. However, other studies focus on how pre-service teachers diagnose (analyse) learning goals, concluding that the participants have difficulties in this task (e.g., Hiebert et al., 2018; Morris \& Hiebert, 2009). According to these authors, two kinds of knowledge or skills are important to diagnose learning goals. One is the mathematical knowledge for teaching and the second is the skill to observe students' thinking in order to identify the nature of the inadequacies or incompleteness.

Despite the research carried out in recent decades, the proposal and definition of specific mathematics objectives claim to be considered as a line of research per se, otherwise as a component of instruction planning (Delong et al., 2005b; Hiebert et al., 2018). "We continually need updated descriptive/analytic studies to uncover, in concrete and specific terms, the actual justification and the goals of mathematics education in different countries/cultures" (Niss, 1996, p. 45).

This study focuses on learning objectives, for "research in mathematics education ...does not consider goal orientation or objectives as an important direction... However, before one tries to improve teaching practice, there should be a decision concerning what one wants to achieve" (Khait, 2003, p. 848). In this way, we intend to contribute to the elaboration and development of a framework of coherent components and related didactic categories, with which to study the statements about educational expectations. Concretely, the goals were to characterize the specific learning objectives for two school mathematics tasks posed by primary teachers in training, and to study the differences in the objectives proposed for each task.

\section{LEARNING EXPECTATIONS LEVELS}

Learning expectations are meant here to be "capabilities, competence, knowledge, know-how, aptitudes, abilities, techniques, skills, habits, values and attitudes that students are expected to achieve, acquire, develop, and use" (Rico \& Lupiáñez, 2008 , p. 66). When considering learning expectations, "all mathematics curricula set out the goals expected to be achieved in learning through the teaching of mathematics; and embed particular values, which may be explicit or implicit" (ICMI, 2018, p. 910).

Over the years, expectations around classroom mathematics learning have been present in curricula for different levels, from general to specific, and ultimately deemed to be the most important element in the curriculum (Tyler, 1949). These normative documents define general ends for the education system, purposes for the stage and period of education, aims for the area or field, or specific objectives for the subjects delivered each year and competence in the discipline, among others (Rico \& Lupiáñez, 2008). Niss (1996) establishes four levels of expectations, ranging from ends as long-term results, to objectives, which are concrete results that can be achieved in the short term and are easy to achieve. Among them are the purposes and aims: "I shall be using the word goal as a comprehensive ('umbrella') term for a variety of related terms such as 'end', 'purpose', 'aim', 'objective'. These terms are supposed to be listed in increasing order of specificity and closeness” (Niss, 1996, p. 15).

The various domains, norms, and levels of learning expectations laid down in legislation on education must be borne in mind when planning a classroom lesson (Reys et al., 2007). However, curricula neither may not owe enumerate each single teacher's priority for a particular lesson. When planning lessons, teachers must reflect on and define their own expectations, for neither institutional documents nor school manuals provide such detailed information. In this level, we distinguish two orientations when expressing specific objectives: teaching oriented objectives and learning oriented objectives. The former express teaching aims: descriptions of the instructional role of the task. The latter express the learning achievements pursued and should address criteria such as specificity, premeditation, deliberateness, cognitive indivisibility and compatibility (Delong et al., 2005a). As the actors responsible for students' learning, teachers stake out the priorities and intentions, i.e., the specific learning objectives, they deem imperative for a given lesson. Within this range, in this work we focus on the specific learning objectives, which are also known as specific educational objectives (Taba, 1962), or simply specific objectives.

\section{OBJECTIVES AND CURRICULAR APPROACHES IN MATHEMATICS EDUCATION}

In mathematics education, objectives, understood to be a general notion encompassing all the intents and purposes pursued with an action, were reviewed and developed in the twentieth century (Delong et al., 2005a). The notion has been included in several countries' education current curricula where it is generally defined as "tools for clarifying thinking, breaking down learning into component parts, creating a logical order to learning, and demonstrating that a learning intervention is successful" (Gander, 2006, p. 9).

Curricular changes occurred over the years have affected the proposed learning objectives (Kilpatrick, 2009). So, learning objectives about school mathematics have been presented in the curricular documents with different aspects. For example, Orstein (1987) highlights four curricular approaches-Behavioral-rational, Managerial-system, Intellectual-academic, HumanisticAesthetic-for a general curriculum. Specifically, for the mathematics curriculum, authors as Howson, Keitel, and Kilpatrick (1981) emphasize five approaches, named Behaviourist, New-Math, Structuralist, Formative, and Integrating-Teaching. More recently, Burkhardt (2014) sets out characteristic of four groups that promote their priorities for teaching and learning mathematics, naming the groups Basic-skills people, Mathematical literacy people, Technology people, and Investigation people. In this paper, we assume the four curricular approaches (instrumental, structural, functional, and comprehensive) claimed by Rico and Lupiáñez 


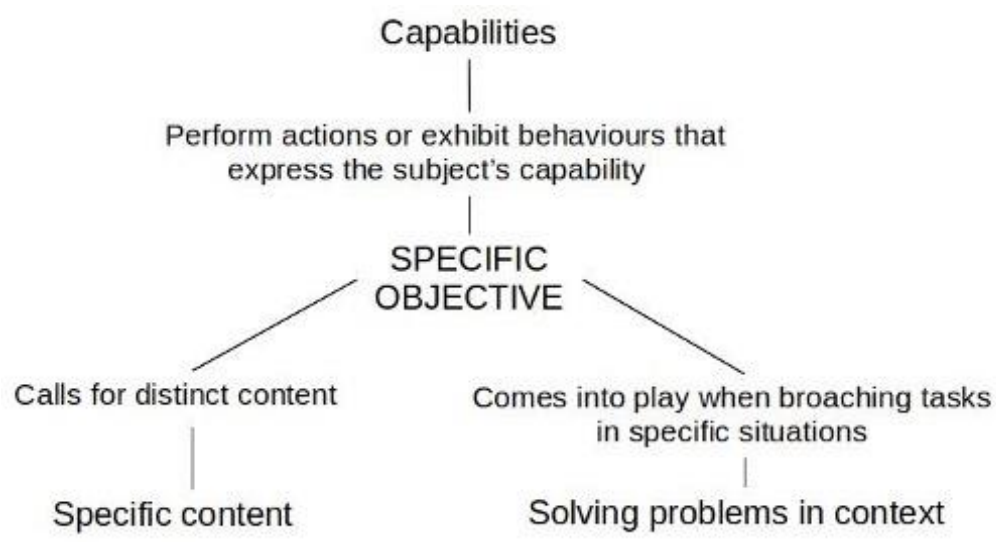

Figure 1. Components of specific objectives (Rico \& Lupiáñez, 2008, p. 68)

(2008) and based on Howson, Keitel and Kilpatrick (1981), since these present different priorities, intents, and purposes to characterize specific objectives of a mathematical task.

The first of these, an instrumental curricular approach, which focuses on the command and use of facts, skills and basic concepts, construed as tools and techniques. Here the priority lies in the mastery of techniques and algorithms useful to furthering certain behaviours and attaining specific objectives. This behavioural influence, highlights learning expectations through very specific statements or operational objectives that emphasize how many and which unique behaviours school students acquire. Objectives express routines, behaviours or specific skills to be achieved that must be observed in the behaviour of students. In the second, named structural approach, knowledge consists in a structured system of formalised rules and concepts based on the deduction. Priority is accorded to a command of relationships and properties. This approach considers learning objectives from a cognitive point of view prioritizing the acquisition of knowledge. The third one, functional approach, stresses knowledge with which to model real situations and is geared to solving problems and issues in different contexts. The purpose is to develop mathematical competence in a variety of contexts and to further functional thinking. Learning objectives are specified through tangible achievements, skills to function in society and applicable to everyday life. Lastly, in the comprehensive approach, knowledge is the outcome of independent intellectual activity, and the training is based on creativity. Objectives do not express concrete results or observable skills, but the development of reasoning and divergent thinking.

\section{Approach to Specific Mathematics Objectives}

In this study we adopted proposal for specific mathematics objectives of Rico and Lupiáñez (2008). That proposal enlarges on the traditional structure for objectives based on behaviour or process and content: "the most useful form for starting objectives is to express them in terms which identify both the kind of behaviour to be developed in the student and the content or area of life in which this behaviour is to operate" (Tyler, 1949, p. 46-47). According to Rico and Lupiáñez (2008), objectives specifically describe the observable performance to be developed through distinct skills, i.e., they describe what students should be able to do (Zabalza, 2000). Structurally speaking, the present proposal deems that specific objectives should be formulated around the three components illustrated in Figure 1.

The first component refers to the capability or capabilities that translate into actions or performance expected of students. The second to the mathematical content to which such actions are geared. The third, not traditionally deemed to be a structural component of objectives, incorporates the context in which content and capabilities are meaningfulness used and applied. As an example, the objective "to identify and interpret rational numbers in simple numerical texts encountered in everyday life in the press, advertising, brochures, or magazines" stipulates the capabilities to be identified and interpreted; rational numbers as the respective mathematical content; and numerical texts routinely found in brochures, magazines, advertising and so on as the context. This proposal of components is considered in this work with analytical character, since they were part of the university training of the participants.

\section{METHOD}

Since mixed methods provide a better understanding of the problem because provide different types of information, to carry out the objective, we deployed an exploratory sequential mixed method. In this method "the research first begins exploring with qualitative data and analysis and then uses the findings in a second quantitative phase" (Creswell, 2014, p. 289). The qualitative phase was used to response the first research aim-to characterize the specific learning objectives for two school mathematics tasks posed by primary teachers in training-, and the quantitative phase for the second one-to study the differences in the objectives proposed for each task. The survey participants, questionnaire, procedure, data classification, coding and content analysis are discussed hereunder.

\section{Participants}

Eighty students working toward a degree in Primary Education at the University of Granada, participated in the study. In Spain, pre-service training for primary education teachers is very general in nature. In the earlier years of their training, the participants 
A sixth year primary education mathematics textbook contains the following problem:

Represent the fraction $2 / 3$

Question: Describe the expectations informing this task in terms of student learning.

Figure 2. Task R posed to the participants

A sixth year primary education mathematics textbook contains the following problem: The drawing below shows a group of girls and a group of boys, each with a number of pizzas. Assuming the pizzas are shared equitably in each group, who gets more pizza, a boy or a girl?

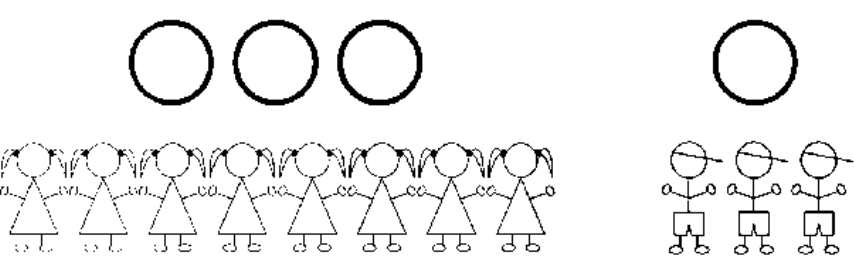

Question: Describe the expectations informing this task in terms of student learning.

Figure 3. Task $\mathrm{P}$ posed to the participants

Table 1. Elements of the tasks proposed

\begin{tabular}{cccccc}
\hline Task & Statement & Representation & Context & Capability & Process \\
\hline $\mathrm{R}$ & Closed & Numerical & No & Representation & Use \\
\hline $\mathrm{P}$ & Open. Narrative & Figurative & Yes & Problem solving & Interpret \\
\hline
\end{tabular}

had taken three courses on mathematics education: school mathematics content, learning mathematics, and teaching mathematics. In its formation, during the second and third year, the specific objectives as didactic notion is worked on. The practice of future teachers on specific objectives is organized into two fundamental skills:

- Analysis of the specific objectives that a task develops, from the identification of the three components: the mathematics content, fundamental capacities, and context or situation,

- Design of a task for a topic and cycle determined from the statement of a given specific objective.

The training received in the third year is based on the planning and sequencing of various tasks in work sessions that contribute to the achievement of a list of specific objectives related to a school mathematical topic and concrete cycle. This list of specific objectives comes from the design of a didactic planning.

As the participants had not been forewarned about the questionnaire, they comprised a convenience sample of pre-service teachers in the final stage of their university studies (Cohen, Manion, \& Morrison, 2011, p. 143).

\section{Instruments}

The instrument used to collect the basic information was a questionnaire with two tasks (all involving rational numbers) used as reactive (Figures 2 \& 3). Participants were told that the tasks were drawn from a sixth-year primary school textbook. The first question, analysed here, asked them to describe the learning objectives for the primary school students performing the task proposed. The tasks used as reactive are shown in Figures 2 and $\mathbf{3}$.

The choice of content involving fractions was not arbitrary: it is and has long been prominent on international curricula and recent research deems it to be significant (Brousseau, Brousseau, \& Warfield, 2014). The tasks were selected for having been used in earlier research (Charalambous \& Pitta-Pantazzi, 2007; Cluff, 2005; Lamon, 1993), and in the analysis of the tasks found that they differed in terms of what students were to do. The task $\mathrm{R}$ asked them to represent a fraction. The conceptual fact involved was a fraction expressed numerically, which they were to represent using a model, normally for area. From the standpoint of representation, it consisted in converting from one system to another. The task $\mathrm{P}$, a word problem containing figurative elements, was a Lamon "associated sets" category exercise (Lamon, 1993). The most prominent elements of each task are summarized in Table 1.

\section{Procedure}

To detect possible instrument error, we conducted a pilot test with a small group of pre-service teachers two weeks before their final exam. As the tasks proposed proved to be clear, they were left unchanged. At the end of the academic year, the pre- 
Table 2. Example of content analysis: reply P19

\begin{tabular}{|c|c|c|c|c|c|}
\hline Information unit & Teacher capacity & Student capacity & Mathematics content & Context & Curricular approach \\
\hline $\mathrm{P} 19 \mathrm{a}$ & Unspecified & Learn to divide & Split into equal pieces & Personal & Functional \\
\hline $\mathrm{P} 19 \mathrm{~b}$ & Unspecified & Apply different combinations & Unspecified & Personal & Functional \\
\hline
\end{tabular}

service teachers answered the questionnaire individually in a single 20-minute session in the presence of the lecturer and one of the researchers. Half of the subjects answered questionnaire R and the other half of them questionnaire P randomly.

\section{Information Units}

The information unit was deemed to be the simplest wording of the objective, such as in response R22: "for the student to represent fractions graphically". Some replies were deemed to contain several information units when different units of the respondent's reply met at least one of the following conditions ( $\mathrm{R}$ is respondent $\mathrm{n}$ 's reply to task $\mathrm{R}$, whereas Pm is respondent m's reply to task P):

- They included more than one verb but no subordinate clauses. For instance, reply P39 "for the children to equate fractions and determine which is larger", contained two information units: P39a ("for the children to equate fractions") and P39b ("for the children to determine which is larger")

- They expressed more than one mathematical notion with just one verb. Reply R02, for instance ("Verify the extent to which they grasp the notion of fractions and how they can be represented") included two units: R02a ("verify the extent to which they grasp the notion of fractions") and R02b ("verify the extent to which they grasp the various ways they can be represented").

Each information unit is composed by a pupil capability, a mathematical concept and a context in which it should be applied (attending Figure 1). Using this structure for dividing the replies into independent information units, they resulted in 79 units for task R and 72 for $P$.

\section{Data Analysis: Qualitative Stage}

In the first stage of qualitative character, the internal structure of participants' replies was defined by studying their semantics categories further to a rigorous methodological procedure governed by clear and systematic rules for reviewing and verifying written content (Cohen et al., 2011). As discussed in further detail below, the data were classified and presented using the three structural components of a specific objective (Figure 1) and the curricular approaches. The three structural components of specific classroom objectives identified-capability, content, and context-were broken down into categories. The classification by categories served to interpret the understanding about learning objectives expressed by future teachers in the objectives proposed.

Capability component was divided into two categories, teacher capability and student capability, corresponding to goal orientation. The former was found in verbs describing teachers' actions (evaluate, instruct...) and the latter in verbs describing actions expected of students (memorise, calculate, reason...). Verbs or actions were the facts that determined the general or specific nature of the capability defined in the objective, while also indicating whether respondents referred to a teaching or a learning objective, or both.

The second component, mathematics content is considered associated with a given mathematical topic. In the specific case of fractions, the replies envisaged different specific types of formal content, such as equivalence, equality or ordering of fractions, proportion or sharing.

The third component, in turn, contexts, comprised a single category, situations in which the contents and capabilities defined in the objectives were applied. Its values, personal, occupational, social and scientific, were drawn from PISA (OECD, 2017), although not all appeared in the responses.

In relation to the curricular approaches category, synthetized by Rico and Lupiáñez (2008), each information unit takes one of the values of this category-instrumental, structural, functional, and comprehensive.

In addition to the proposed categories in the theoretical framework, we analysed a supplementary category, the number of objectives proposed, i.e., the number of learning expectations-information units-proposed by pre-service teachers in their replies.

The content of reply P19 ("One of the objectives is for students to learn to divide the pizza into as many pieces as possible ensuring that they all get the same amount and to envisage different combinations: i.e., a pizza can be divided into two, four, eight pieces...") is analysed in Table 2 by way of example.

Consistency across different coders, qualitative reliability (Creswell, 2014), was established by researcher triangulation. During seven months, in weekly meetings, seven researchers argued about coherent justification for the different values of each component. The cases were discussed and compared until there were no disagreements.

In addition, to ensure the achievement of the identification of the characteristics of data objectively, we calculated intercoder reliability, understood as agreement between independent coders (Neuendorf, 2002). Five months later, an independent second group of coders repeated the recording of characteristics using the same categories. For measuring the degree of consistency between the two codifications, we used the Holsti's Method-a variation of percentage agreement-due to the second group of coders identified one unit of information more than the first group. Holti's formula is: $R=\frac{2 C}{N_{1}+N_{2}}$ where $\mathrm{R}$ represents percentage of agreement between two coders, $\mathrm{C}$ is the number of two coders' consensus decisions, and N1 and N2 are numbers of decisions 
Table 3. Holsti's coefficients of each category

\begin{tabular}{cc}
\hline Category & Holsti's coefficients \\
\hline Teacher capability & 0.98 \\
\hline Student capability & 0.97 \\
\hline Content & 0.93 \\
\hline Context & 0.98 \\
\hline
\end{tabular}

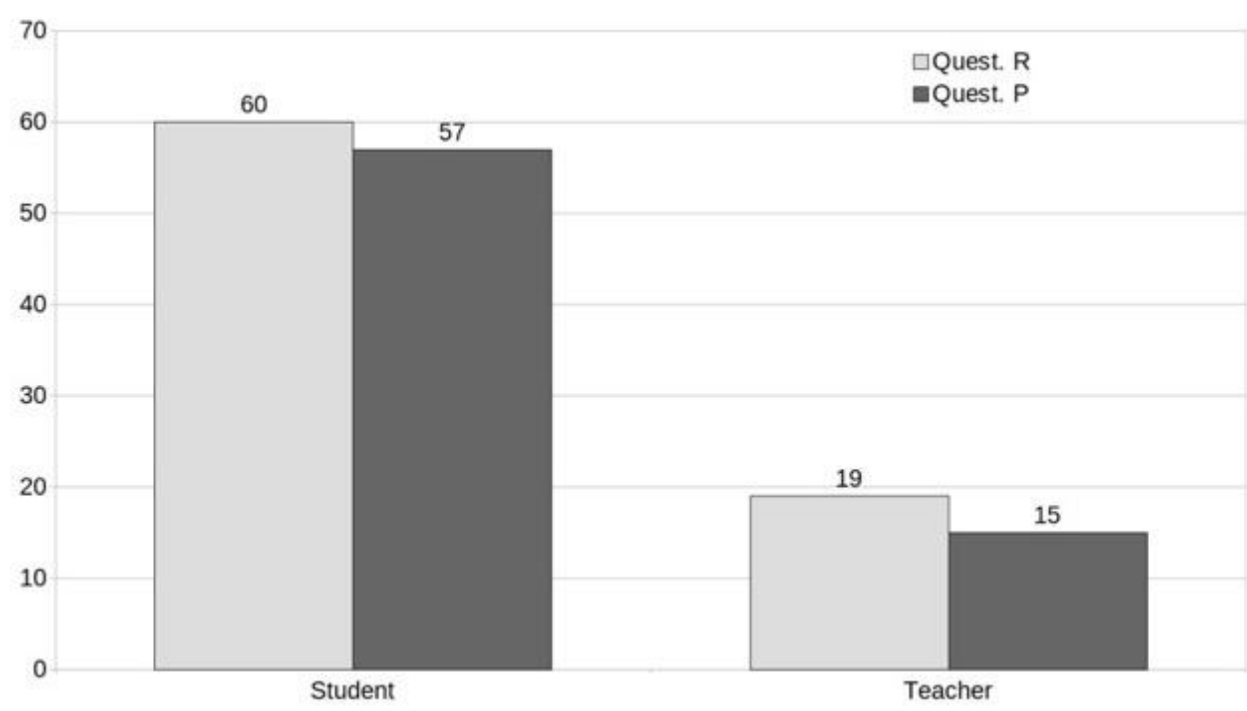

Figure 4. Capability component distribution by task

coders have made respectively. Typically, at least $80 \%$ of agreement is considered good (Guest, MacQueen, \& Namey, 2012). In our codifications, all coefficients are above 0.9 , showing high reliability between the two tests (Table 3 ).

\section{Data Analysis: Quantitative Stage}

In the second phase of quantitative character, the findings from the qualitative categorization of the data were used to perform frequency analysis and hypothesis test. Fisher's exact test (for proportionality) was also run, using R open-source software (version 3.2.3) for statistical computing and graphics. Fisher's exact test reveals the presence of significant differences between units of replies to tasks $\mathrm{R}$ and $\mathrm{P}$. The problem consists in ascertaining whether the proportions of the units are the same on the two tasks for the variables studied. The null hypothesis, $\mathrm{HO}$, is that they are.

\section{RESULTS}

After breaking down the objectives by components and category further to the criteria described, we found a total of 151 information units, 79 for tasks R and 72 for P. A single unit was identified in $39 \%$ of the replies, two in $36 \%$, three in $15 \%$ and four or more in $8 \%$. The analysis findings, frequency and hypothesis test, are presented for the categories defined-capability, specific content, and context.

\section{Frequency Analysis of Capability}

Although the initial guidelines for the two tasks explicitly asked respondents to specify the expectation underlying the task in terms of learning, in some replies the information units referred to teaching objectives (Figure 4) in the form of teacher capabilities. As Figure 4 shows, most of the units focused exclusively on student capabilities (77\%), such as P37a "for students to learn to work with fractions". Teacher capabilities appeared in $23 \%$ of the replies, most of which also included student capabilities, such as in P23a ("to determine whether the children know how to do fractions"). Teachers were the subjects of the unit with no mention of student capabilities in only a few replies. Two examples were R16a "verify students' knowledge" and P27b "assess the lesson on fractions". All but six of the objectives containing references to teachers also mentioned student capabilities.

Ten verbs were deemed to signal teacher capabilities: "ascertain, verify, determine, teach, evaluate, further, aim, know, work, see". Those verbs were often associated with direct objects not included in the previous list. "Verify", for instance, usually appeared with the object "knowledge" and "work" with the prepositional phrase "with the student". R16a provided an example of the former "verify students' knowledge". The most prevalent verbs were "verify", found in $21 \%$ of the units (all on task R), followed by "know whether" and "work", both in 15 of the units.

A total of 38 verbs referring to students were identified. The ones found on both tasks were "acquire, learn, understand/comprehend, be familiar with, do, represent, know (different things), work, use". In a first tally, the verb "to know" was the most frequent, present in 23 units. The verb phrase "know + [how to] infinitive" was present in 12 of the 23 (used by $15 \%$ of the pre-service teachers, such as R38c "know how to split up an amount depending on the fraction"). "To know + concept" 


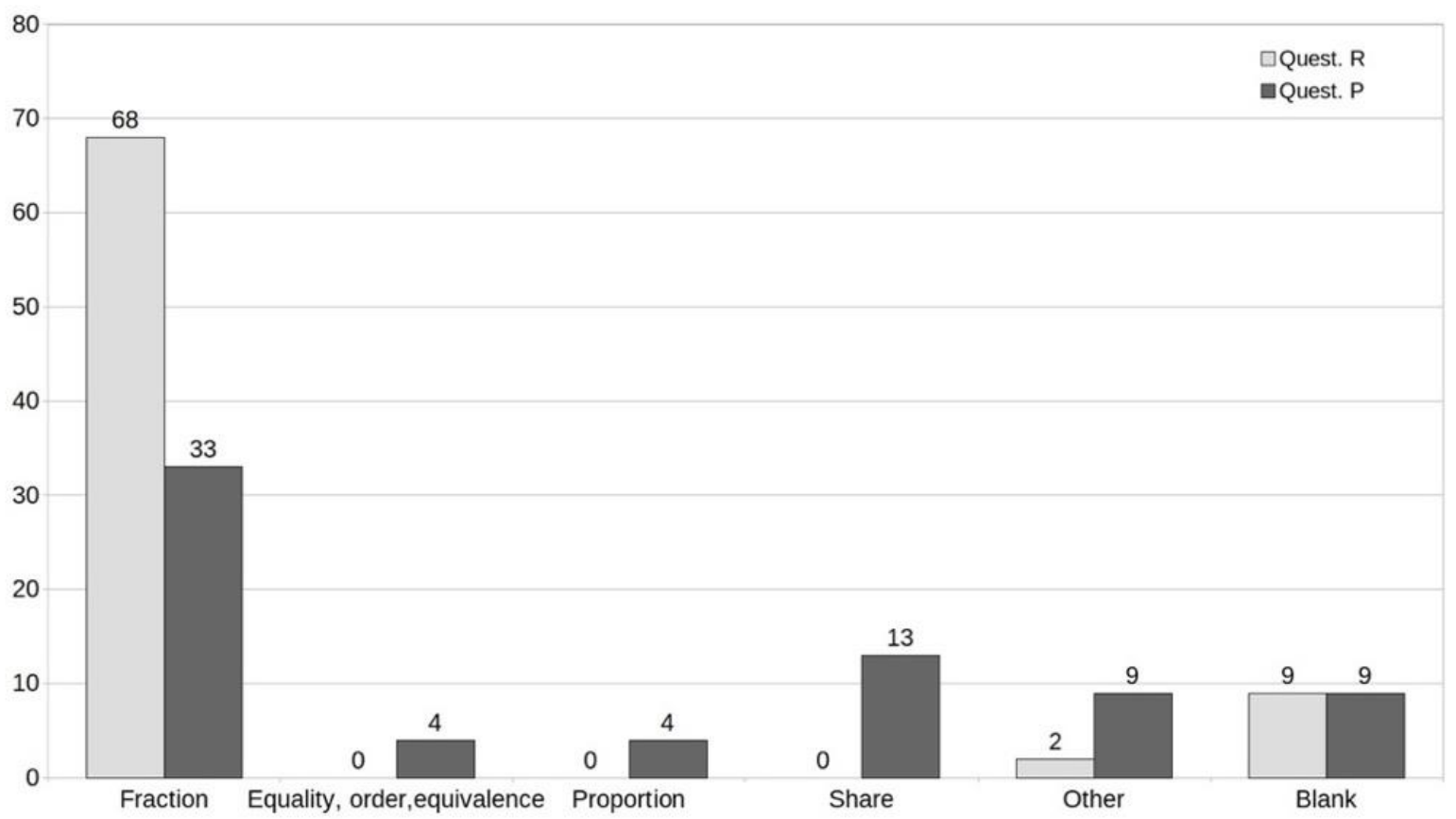

Figure 5. Frequencies of formal content category items

appeared in six units (8\%): R27d "know the components of a fraction (numerator-denominator)". The verbs "to learn" and "to understand" followed the same pattern and were usually associated with other infinitives or a concept (R17a: "learn to split up into equal parts"). Other possibilities were units with no verb, such as in P06a "the equitable sharing concept".

With a view to drawing more meaningful information from the data, a second tally was performed, reinterpreting the verbs "to know", "to learn to" and "to understand" when associated with other verbs. An objective such as "for students to learn to divide the pizza", for instance, was classified as "to divide". This second tally of the 151 units yielded 41 verbs, 29 on task R and 24 on P. The verbs repeated on the two tasks were "acquire, learn, understand/comprehend, determine, be familiar with, identify, do, represent, know (different things), work, use". The one found most frequently on task R was "to represent" (22\%) and on P "to learn" (17\%). Surprisingly, $6 \%$ of the objectives contained neither a verb nor a student capability. Overall, "to represent" was the verb used most ( $13 \%$ of units), followed by "to learn" (10\%), "to work" ( $8 \%$ ) and "to understand" (7\%).

General capabilities (not specifically referred to a mathematical action such as to be familiar with or to learn) accounted for $68 \%$ of the total on both tasks, and specific capabilities (to calculate, compare, split up, equate, convert from one representation to another, visually project, share, represent, solve problems) for $26 \%$, with a surprisingly large number of verb-less units (9.6\% of the total).

\section{Frequency Analysis of Mathematics Content}

Pre-service teachers mentioned a variety of mathematical contents in their replies (Figure 5), including factual information such as denominator, conceits such as fraction or rational numbers and relationships such as order and equivalence. The content item most often repeated was fraction, either on its own (56\%) or in conjunction with other topics such as sharing, numerator, denominator or equivalence. In all, the word fraction appeared in $67 \%$ of the units. Other less frequently found terms included sharing (9\%), proportion/proportionality (3\%) and relationships (equality, order, equivalence-3\%). Content was absent in $12 \%$ of the objectives proposed.

Taking each task separately, on $\mathrm{R}$ the items mentioned were fraction, mathematical language and number, whereas more items were cited on $\mathrm{P}$, including proportion, sharing or the equality, order or equivalence of fractions.

\section{Frequency Analysis of Context}

Of the four situations defined by PISA for contexts (personal, occupational, social and scientific), only two, personal and social, were identified in the replies. R01c was one of the units including a personal situation ("for them to use fractions correctly to solve different types of problems in daily life"). The frequency analysis for this category showed that explicit reference to situations was lacking in $81 \%$ of the units. Although it can be considered normal that the participants did not include context or situation in the responses of task $\mathrm{R}$, a high percentage of responses to task $\mathrm{P}$ did not include it either. Fifteen per cent dealt with a personal and the remaining $4 \%$ with a social situation (Figure 6).

\section{Frequency Analysis of Curricular Approaches}

In relation to the curricular approaches (instrumental, structural, functional, and comprehensive), 56 out of 151 (37\%) of the units exhibited instrumental expectations (e.g., R11a: "The objective of the task is that the student knows how to represent the fraction through a graph, diagram or picture"), and similarly 55 (36.5\%) of the units present a structural approach (e.g., P07a: "To understand the concept of distribution with different quantities"). Those with functional expectations accounted for $20 \%$ (e.g., 


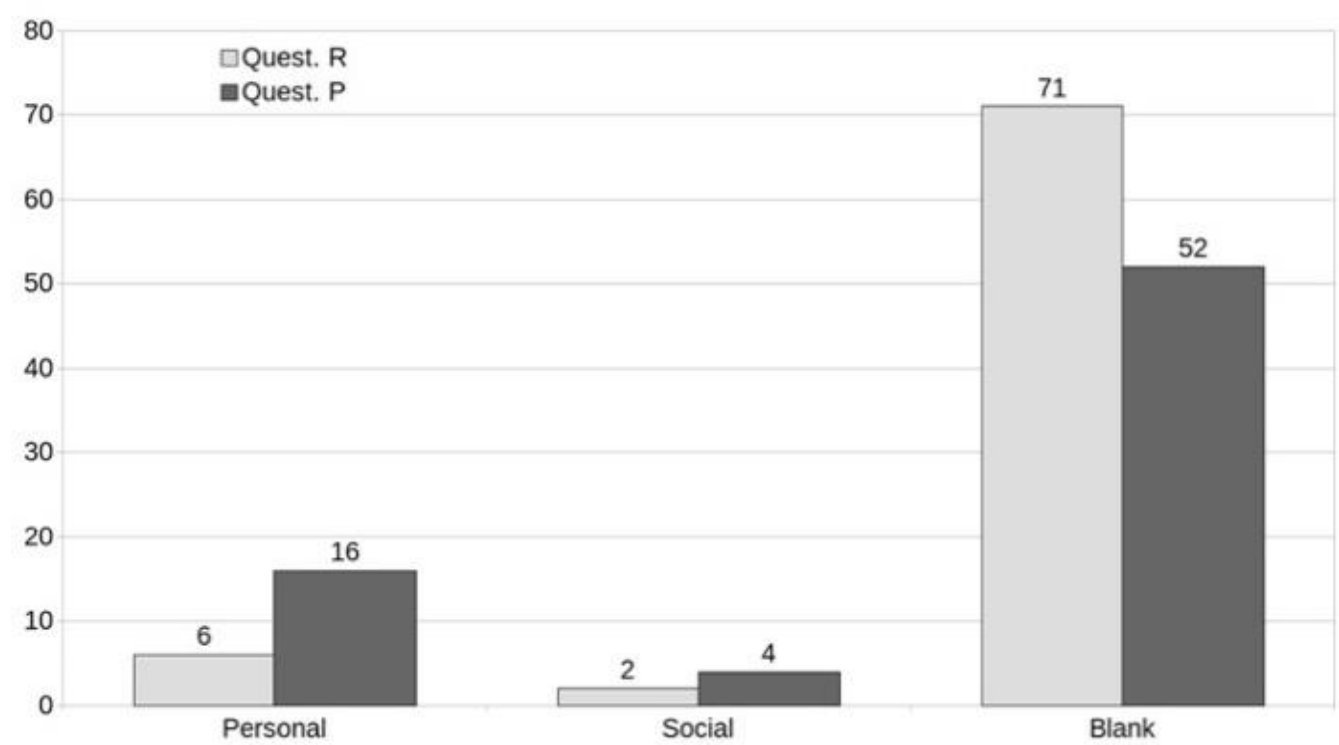

Figure 6. Frequencies of context component items

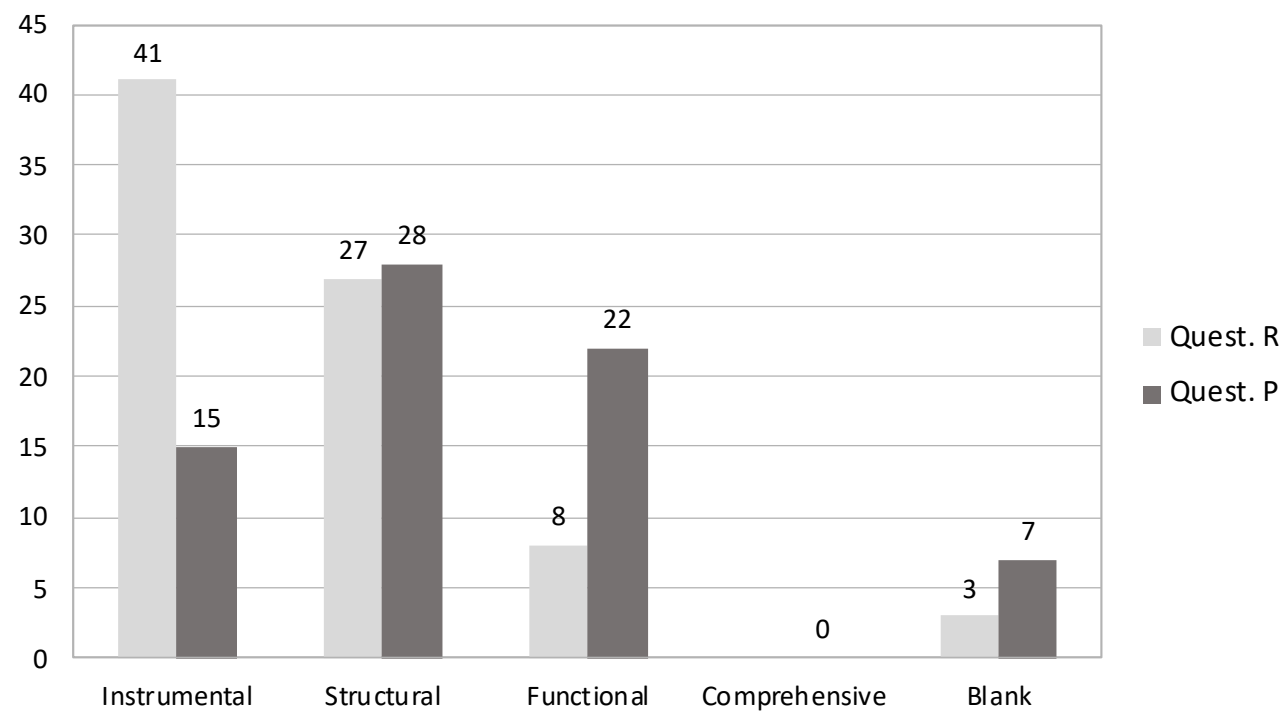

Figure 7. Frequencies of curricular approaches category items

R01c: "To use fractions correctly to solve different types of problems with real contexts"). The comprehensive approach was not identified in any of the units. Differentiating between tasks, a preference for the instrumental (52\%) and structural (34\%) approaches was observed on task R, whereas the structural (39\%) and functional $(30.5 \%)$ approaches were found to prevail on task $\mathrm{P}$.

\section{Hypothesis Testing}

Differences between tasks $\mathrm{R}$ and $\mathrm{P}$ in terms of the units identified were mentioned in the section on data classification. Fisher's exact test was applied to determine which differences were actually significant, category by category. The initial assumption was that the tasks differed in terms of representation, context, mathematical capability, and cognitive level.

As the grouping pattern for the categories number of units and (student or teacher) capability was similar in the two tasks, the test results determined no differences in proportions. In other words, they showed that the differences were not significant. Of the 151 units, 33 (22\%) included teacher capabilities. No difference in proportion was detected between the tasks here either (Table 4). Nor did the breakdown of student capabilities into general and specific yield significant differences by task (Table 5).

In contrast, significant inter-task differences were identified for the component specific content, with regard to both content and representation (Table 6).

Relevant differences were also found for the categories of meaning and the component context. The most conspicuous difference was that whereas $87 \%$ of the task R objectives specified no sense, this category was lacking on only $50 \%$ of the task $\mathrm{P}$ objectives. Significant differences were also observed around the situation in which tasks were contextualised (Table 7). 
Table 4. Fisher's exact test: number of units and capability reference

\begin{tabular}{|c|c|c|c|c|}
\hline & Number & Task $\mathbf{R}$ & Task P & P-value \\
\hline \multirow{4}{*}{ Number of units per reply } & One & 16 & 15 & 0.9298 \\
\hline & Two & 13 & 16 & 0.3689 \\
\hline & Three & 8 & 4 & 0.2996 \\
\hline & Four or more & 3 & 3 & - \\
\hline \multirow{2}{*}{ Capability referred to } & Student & 60 & 57 & 0.6364 \\
\hline & Teacher & 18 & 15 & 0.6364 \\
\hline Total units & & 79 & 72 & \\
\hline
\end{tabular}

Table 5. Fisher's exact test: Category Capability referred to students

\begin{tabular}{cccc}
\hline & Task R & Task P & P-value \\
\hline General & 55 & 48 & 0.6971 \\
\hline Specific & 21 & 18 & 0.8244 \\
\hline None & 3 & 6 & - \\
\hline Total & 79 & 72 & \\
\hline
\end{tabular}

Table 6. Fisher's exact test: Category Content

\begin{tabular}{|c|c|c|c|}
\hline & Task R & Task P & P-value \\
\hline Fraction & 68 & 33 & $1.536 \cdot 10-7$ \\
\hline Relationship (equality, order, equivalence) & 0 & 4 & - \\
\hline Sharing & 0 & 11 & - \\
\hline Proportion & 0 & 4 & - \\
\hline Other & 2 & 9 & - \\
\hline Unspecified & 9 & 11 & - \\
\hline Total & 79 & 72 & \\
\hline
\end{tabular}

Table 7. Fisher's exact test: Component Context

\begin{tabular}{cccc}
\hline & Task R & Task P & P-value \\
\hline Personal & 6 & 16 & - \\
\hline Social & 2 & 4 & \\
\hline Unspecified & 71 & 52 & \\
\hline Total & 79 & 72 & \\
\hline
\end{tabular}

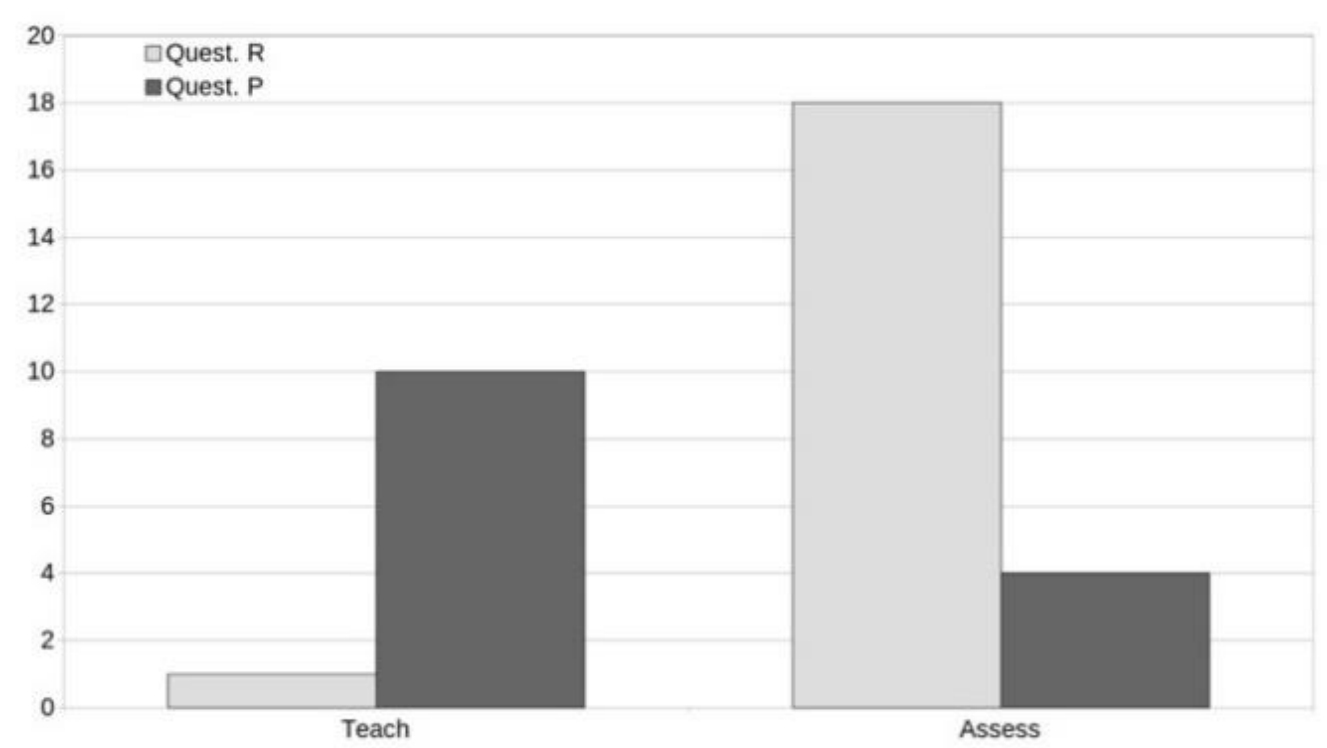

Figure 8. Teacher capability-related expectations by task

Although the tasks asked respondents to describe expectations in terms of student learning, in 33 units (19 on task R and 14 on $\mathrm{P}$ ) they referred not only to student but also to teacher capabilities. On those grounds, we proceeded to an initial classification by the actor involved.

For teachers, the expectations were divided into those aiming to assess (evaluate, verify, know whether, see whether...) and those aiming to instruct (teach, foster, work...). The findings (Figure 8) showed that nearly all (18) the replies to task R were assessment-related, whereas units denoting instructional expectations prevailed (10 of 14) in the responses to task P.

With a p-value of 0.0000675 , the Fisher's exact test findings indicated that the expectations cited on the two tasks differed significantly. 


\section{DISCUSSION}

Summarising in terms of the three components of specific objectives, the capability "to represent" prevailed in the first component, although when the objectives were arranged into specific and general, the latter (to learn, to understand...) were observed to predominate. The most prominent mathematical content was "fraction", expressed in terms of skills (Figure 5). The component context was likewise largely absent from the units. The units most frequently found were consequently worded as "to represent fractions" or "to learn fractions".

The second part of the analysis yielded information on the statistically significant differences between the tasks. Differences were identified for the content and context components. In the former, they were observed in mathematical content and the respective cognitive level. The mathematical content prevailing in both tasks was "fraction", although much more prominently in $\mathrm{R}$ than $\mathrm{P}$, where "sharing" was also very frequent. That may be explained by what was specifically involved in each task. Whilst context was largely absent in both tasks, its relative presence varied, with personal situations cited more prominently in P. In a nutshell, a unit representative of task R might be "to represent the numerator and denominator of a fraction", whereas an example typical of P might be "to learn to share pizzas".

By way of summary, the expectations in task $\mathrm{R}$ were assessment-related (when referred to teachers) and denoted an instrumental approach on the part of pre-service teachers, i.e., the emphasis was on techniques and algorithms useful for furthering certain behaviours. The task $\mathrm{P}$ units were characterised by instructional objectives (when referred to students) and a structural approach. In other words, knowledge was assumed to consist in a structured system of formalised rules and concepts.

\section{CONCLUSIONS}

Inasmuch as learning expectations are the basis for planning in compulsory education, this study sought characterize the specific learning objectives for two school mathematics tasks posed by primary teachers in training, and to study the differences in the objectives proposed for each task. For this purpose, objectives expressed by teachers in training were broken down into three components, namely capability, content, and context, revealed relevant information about participants' ability to formulate learning objectives. By using the system of categories and components, all the proposals could be interpreted coherently.

Concretely, the capabilities of the proposed objectives were expressed in the form of general verbs such as "to learn", "to know" or "to be familiar with". They also encompassed both teacher and student capabilities, even though respondents were explicitly asked to reply only in terms of learning. The types of specific content referred to in the replies included both conceptual and procedural contents. With respect to the third component, context, was largely absent from the responses, with only minimal mention of personal or classroom-related situations. Hence, the results suggest that context is not considered by the participants when stating objectives. This fact increases when the task used as reactive does not have a situation (represents fraction $2 / 3$ ). We consider these findings as relevant, since these components are not considered in other studies (Delong et al., 2005a; Hiebert et al., 2018; Lupiáñez \& Rico, 2011; Morris \& Hiebert, 2009).

Interpreting the objectives in terms of the curricular approaches, the responses show both an instrumental approach-where knowledge consists in mastering techniques and algorithms useful to furthering certain behaviours and attaining specific objectives-and a structural approach-where knowledge consists in a structured system of formalized rules and concepts based on the deduction. Moreover, this expectation depends on the kind of school task. Highlights that these approaches are far from a current vision of mathematics based on the development of competencies.

Similar to what happens when pre-service teachers analyse objectives (Hiebert et al., 2018), our findings show that to propose objectives is not a trivial task. This teaching competence is not immediately apparent or intuitive (Hiebert et al., 2018; Lupiáñez \& Rico, 2011). So, it can be acquired through well-developed courses in a teacher preparation program, where they can be worked through a rational process, and not as an isolated competency and trained as a separate skill. This training could help teachers to stop the tendency to treat learning objectives as check-off items to be completed (Gander, 2006), or to appropriate others already proposed (Delong et al., 2005b). Pre-service training must be improved to attach greater importance to learning objectives and tools must be furnished for their formulation. Those are imperatives to highlighting the relevance of objectives in classroom planning.

With this study, we have obtained and contrasted useful evidence to structure the specific learning objectives for school mathematics manifested by pre-service teachers. We hope that a controlled review of the results will confirm their interest and will broaden the future perspective of the stated purposes, refining and improving their empirical base and theoretical foundation required.

Author contributions: All authors have sufficiently contributed to the study, and agreed with the results and conclusions.

Funding: This research was funded by Ministry of Science, Innovation and Universities (Spain) who finances the research project PGC2018095765-B-I00 (PROFESTEM).

Declaration of interest: No conflict of interest is declared by authors. 


\section{REFERENCES}

Aguayo-Arriagada, C. G., Flores, P., \& Moreno, A. (2018). Concepto de objetivo de una tarea matemática de futuros maestros. Bolema, 32(62), 990-1011. https://doi.org/10.1590/1980-4415v32n62a12

Brousseau, G., Brousseau, G., \& Warfield, V. M. (2014). Teaching fractions through situations: A fundamental experience. Springer. https://doi.org/10.1007/978-94-007-2715-1

Burkhardt, H. (2014). Curriculum Design and Systemic Change. In Y. Li \& G. Lappan (Eds.), Mathematics Curriculum in School Education (pp. 13-34). Springer. https://doi.org/10.1007/978-94-007-7560-2_2

Carrillo, J., Climent, N., \& Contreras, L. C. (2013). Determining specialized knowledge for mathematics teaching. In B. Ubuz, C. Haser, \& M. A. Mariotti (Eds.), Proceedings of the CERME 8 (pp. 2985-2994). Middle East Technical University, ERME.

Charalambous, C. Y., \& Pitta-Pantazi, D. (2007). Drawing on a theoretical model to study students' understandings of fractions. Educational Studies in Mathematics, 64(3), 293-316. https://doi.org/10.1007/s10649-006-9036-2

Chen, J. C., Reys, B. J., \& Reys, R. E. (2009). Analysis of the learning expectations related to grade 1-8 measurement in some countries. International Journal of Science and Mathematics Education, 7, 1013-1031. https://doi.org/10.1007/s10763-008-91485

Cluff, J. J. (2005). Fraction multiplication and division image change in pre-service elementary teachers (Doctoral dissertation). Brigham Young University.

Cohen, L., Manion, L., \& Morrison, K. (2011). Research methods in education. Routledge.

Creswell, J. W. (2014). Research design: Qualitative, quantitative, and mixed methods approaches (4 ${ }^{\text {th }}$ ed.). Sage publications.

DeLong, M., Winter, D., \& Yackel, C. (2005a). Student learning objectives and mathematics teaching. PRIMUS, 15(3), $226-258$. https://doi.org/10.1080/10511970508984119

DeLong, M., Winter, D., \& Yackel, C. (2005b). Mental maps and learning objectives: The FAST-SLO algorithm for creating student learning objectives. PRIMUS, 15(4), 307-338. https://doi.org/10.1080/10511970508984126

Gander, S. L. (2006). Throw out learning objectives! In support of a new taxonomy. Performance Improvement, 45(3), 9-15. https://doi.org/10.1002/pfi.2006.4930450304

Guest, G., MacQueen, K. M., \& Namey, E. E. (2012). Applied thematic analysis. Sage. https://doi.org/10.4135/9781483384436

Hiebert, J., Morris, A. K., \& Spitzer, S. M. (2018). Diagnosing learning goals: an often overlooked teaching competency. In T. Leuders, K. Philipp, \& J. Leuders (Eds.), Diagnostic competence of mathematics teachers. Mathematics Teacher Education (vol. 11, pp. 193-206). Springer, Cham. https://doi.org/10.1007/978-3-319-66327-2_10

Howson, G., Keitel, C., \& Kilpatrick, J. (1981). Curriculum Development in Mathematics. Cambridge University Press. https://doi.org/10.1017/CBO9780511569722

International Commision on Mathematical Instruction (2018). ICMI Study 24. School Mathematics curriculum reforms: Challenges, changes and opportunities. Discussion document.

Khait, A. (2003). Goal orientation in mathematics education. International Journal of Mathematical Education in Science and Technology, 34(6), 847-858. https://doi.org/10.1080/00207390310001595438

Kilpatrick, J. (2009). The mathematics teacher and curriculum change. PNA, 3(3), 107-121.

Lamon, S. J. (1993). Ratio and proportion: Children's cognitive and metacognitive processes. In T. P. Carpenter, E. Fennema, \& T. A. Romberg /Eds.), Rational numbers: An integration of research (pp. 131-156). Lawrence Erlbaum Associates.

Landmann, M. (2013). Development of a Scale to Assess the demand for specific competences in teachers after graduation from university. European Journal of Teacher Education, 36(4), 413-427. https://doi.org/10.1080/02619768.2013.837046

Lin, C., Hung, P., Lin, S. W., Lin, B., \& Lin, F. (2009). The power of learning goal orientation in predicting student mathematics achievement. International Journal of Science and Mathematics Education, 7, 551-573. https://doi.org/10.1007/s10763-0089132-0

Lupiáñez, J. L., \& Rico, L. (2011). Statement of specific objectives in a mathematics teacher training program. XIII Inter-American Conference on Mathematics Education. Recife, Brazil.

Morris, A. K., \& Hiebert, J. (2009). Introduction: Building knowledge bases and improving systems of practice. The Elementary School Journal, 109, 429-441. https://doi.org/10.1086/596994

Neuendorf, K. A. (2002). The content analysis guidebook. Sage.

Niss, M. (1996). Goals of Mathematics Teaching. In A. Bishop et al. (Ed.) International Handbook of Mathematics Education (pp. 1147). Kluwer Academic Publishers. https://doi.org/10.1007/978-94-009-1465-0_3

OECD. (2017). PISA 2015 Assessment and Analytical Framework: Science, Reading, Mathematic, Financial Literacy and Collaborative Problem Solving, revised edition. PISA, OECD Publishing. https://doi.org/10.1787/9789264281820-en

Ornstein, A. C. (1987). The Field of Curriculum: What Approach? What Definition? The High School Journal, 70(4), $208-216$.

Petrou, M., \& Goulding, M. (2011). Conceptualising teachers' mathematical knowledge in teaching. In T. Rowland \& K. Ruthven (Eds.), Mathematical knowledge in teaching (pp. 9-25). Springer. https://doi.org/10.1007/978-90-481-9766-8_2

Putra, Z. H. (2019). Danish pre-service teachers' mathematical and didactical knowledge of operations with rational numbers. International Electronic Journal of Mathematics Education, 14(3), 619-632. https://doi.org/10.29333/iejme/5775

Reys, R. E., Lindquist, M., Lambdin, D. V., Suidam, M., \& Smith, N. L. (2007). Helping children learn mathematics. Wiley. 
Rico, L., \& Lupiáñez, J. L. (2008). Competencias matemáticas desde una perspectiva curricular [Mathematical competences from a curricular perspective]. Alianza Editorial.

Rico, L., \& Ruiz-Hidalgo, J. F. (2018). Ideas to work for the curriculum change in school Mathematics. In Y. Shimizu \& R. Vithal (Eds.), Conference proceedings of the twenty-fourth ICMI Study: School Mathematics curriculum reforms: Challenges, changes and opportunities (pp. 301-308). International Commission on Mathematical Instruction and University of Tsukuba.

Sullivan, P., Clarke, D., Clarke, B., \& O'Shea, H. (2010). Exploring the relationship between task, teacher actions, and student learning. PNA, 4(4), 133-142. https://doi.org/10.30827/pna.v4i4.6163

Taba, H. (1962). Curriculum development. Theory and practice. Harcout, Brace \& World.

Tyler, R. W. (1949). Basic principles of curriculum and instruction. University of Chicago Press.

Zabalza, M. A. (2000). Diseño y desarrollo curricular [Currilulum design and development]. Narcea. 